\title{
Barriers of Reporting Incident and Suggested Sloutions from the Perspective of Staff Nurses
}

\author{
SAMAH B. MOURD, M.Sc.; ABEER M. SEADA, D.N.Sc. and EMAN A. ETWAY, D.N.Sc.
}

The Department of Nursing Administration, Faculty of Nursing, Cairo University

\begin{abstract}
Background: Incident reporting in health care is considered a way to monitor, prevent, and reduce the occurrence of patient safety events. "Incident Reporting Systems, (IRS) will continue to be an important influence on improving patient safety and quality of health care.
\end{abstract}

Aim: The aim of this study is to assess barriers of reporting incident report and suggested solutions from the perspective of staff nurses.

Material and Methods: Descriptive exploratory study design was utilized to collect data in this study. Convenient sample of staff nurses $(\mathrm{N}=250)$ who were working in all inpatient departments at 6 October Health Insurance Hospital in Giza. Two tools were used for data collection: Barriers of reporting incident and suggested solutions questionnaires.

Results: Results of the present study revealed that, the highest mean scores regarding barriers of reporting incident was time constrain, while the lowest mean scores was lack of education. While regarding suggested solutions, the highest mean scores was availability of reports pathways, while the lowest mean scores was regarding to valuing reporting.

Conclusion: The main barrier for reporting incident barriers was time constrains and the main suggested solutions, was availability of reports pathways.

Recommendation: The hospital administrators should introduce reward systems, and improving incident reporting systems by including a variety of reporting channels and ensuring reporter anonymity, and creating a strong safety culture within the hospital.

Key Words: Incident report-Barriers - Suggested solution - Staff nurses.

\section{Introduction}

DEVELOPING a patient safety culture in a healthcare facility is among the priority recommendations by the international health community and incident reporting has been considered as an indispensable pillar [1]. Reporting nursing incidents is an essential

Correspondence to: Dr. Samah B. Mourd, The Department of Nursing Administration, Faculty of Nursing,

Cairo University component of patient safety enhancement and quality of care improvement and it should be an integral part of the organizational culture because errors everlasting threats to patient safety [2]. An incident report should be completed each time an event occurs that deviates from the normal operation of the facility or deviates from routine patient care. An incident is defined as an event or circumstance that could have resulted, or did result, in unnecessary harm to a patient [3]. Incident reports can be completed by any licensed healthcare professional who participated in or witnessed an incident. Writing an incident report should never be delegated to unlicensed personnel although unlicensed personnel should report any witnessed incidents and provide information that can be included in the incident report and are rarely completed in the presence of a patient's family members [4].

Despite the importance of reporting incidents in enhancing patient safety and quality of care, medical errors are largely underreported across health care organizations [5]. Underreporting makes incident reporting less useful, not least because the reports that are submitted provide a biased snapshot of issues within a health care organization [6]. One of the major weaknesses of incident reporting, which is likely to contribute to underreporting, is that health care professionals tend not to gain feedback or see action taken after they report an adverse event [6].

There are now many studies that document barriers to effective incident reporting in health care. Among those barriers are fear of blame and repercussions, nurses workload, poor usability of incident reporting systems, definitional problems about what constitutes an adverse event rather than a complication [7]. Other barriers incident reporting including resource constraints, uncertainty about 
what to report, apathy about reporting and its value, unfamiliarity with the reporting system, and fear of getting in trouble or getting someone else in trouble [8]. In addition to lack of feedback to staff who report incidents, and lack of visible improvements to the local work environment as a result of reported incidents [9]. Furthermore, there is a lack of time because of complex reporting processes and forms, a lack of understanding and clear definitions of reportable errors.

Some suggestions have been offered to improve medical error reporting, in order to motivate and reinforce healthcare personnel in this direction. Those suggestions include education and the development of awareness about reporting, dissolution of the atmosphere of fear and potential risks as a consequence of reporting, delivery of constructive feedback in a reasonable amount of time, shortening of the reporting duration, and development of strategies to encourage reporting by administrators [8]. Christiaans [9] and Marquis [10] stated that the incident reporting system is used to enhance quality of care and patient safety; so it is imperative to evaluate incident reports systematically and to learn lessons from adverse and potential adverse incidents to patients.

\section{Significance of the study:}

Millions of patients worldwide have experienced deaths or disabling injuries due to errors in the healthcare system [11]. The World Health Organization (WHO) estimates that adverse events accounts annually for 850.000 patient safety incident in the United Kingdom Department of Health. In the developed world around $10 \%$ of all hospital admissions involve a patient incident of adverse character with one out of three incidents leading to patient death or disability [12]. From the researcher clinical observations and experience as trainer in a selected health insurance hospital, it was observed that much errors occur with no reporting of such errors as a result the same errors repeatedly occur and patient encounter preventable damage and adverse events. Many researches have been conducted in Egypt concerning factors contributing to errors such as medication errors as well as reporting behavior as perceived by nurses [23] While there is still a gap in the literature concerning barriers of reporting incident and suggested solutions.

Therefore, the present study is aiming to assess barriers of reporting incident and suggested solutions from the perspective of staff nurses.

\section{Subjects and Methods}

\section{Research questions:}

The following research questions were guided this research:

1- What are the barriers of reporting incident from staff nurses' perspective?

2- What are the suggested solutions for reporting incident from staff nurses' perspective?

\section{Research design:}

Descriptive exploratory study design was utilized to achieve the aim of this study.

Setting: The study was conducted at 6 October Health Insurance Hospital with bed capacity is 286 beds, this hospital had abed capacity of 286 beds classified as the follows medical (55 beds), surgical ( 60 beds), ICU ( 35 beds), hemodialysis (40 beds), open heart surgery ( 21 beds), emergency ( 30 beds), cardiac catheterization ( 25 beds) and endoscopy (20 beds). Data was collected for three months from the beginning of November 2017 till the ending January 2018.

Subject: Convenient sample of staff nurses who working in the selected Health Insurance Hospital. The total sample size was (250) staff nurses out of (318) staff nurses.

Inclusion criteria: Staff nurses who took a daily patient assignments, provide direct patient care, accepted to participated in the study and have at least 1 year of experience.

\section{Tools of data collection:}

Data for the present study was collected through utilizing the following two tools as:

1- Barriers of reporting incident questionnaire, it includes two parts:

1st part: Personal characteristics of staff nurses as: Age, gender, employment statue, years of experience, qualification and department name.

2nd part: This tool was developed by Evans, Smith, Esterman, [25] and modified by the investigator to assess barriers of reporting incident, it consists of 36 items, divided into 6 dimensions as follows: Culture of shame and blame (9) items, lack of education (6) items, time constraints (6) items, a sense of futility (7) items, lack of feedback (5) items, reports view as indicators of incompetence (3) items. The respondents' scoring system checks their answers using five-point Likert scale ranged from strongly disagree (1) to strongly agree (5). 
2nd tool: Suggested solutions questionnaires: Developed by (National Health Services) NHS quality improvement Scotland [17], Wolf and Hughes [26], and modified by the investigator to assess the suggested solutions for reporting incident from staff nurses' perspective. It was consists of [16] items divided into (4) dimensions: Valuing reporting (3) items, availability of reports pathway (6) items, feedback and visible changes (4) items, training and education (3) items. Each item ranked on Likert scale ranging from (1) strongly disagree to (5) strongly agree.

\section{Validity \& reliability:}

Content validity was established by three expertise. Professors from Nursing Administration Department at Faculty of Nursing, Cairo University. In the light of their recommendations, the important adjustment were produced. Reliability test was done for barriers of reporting incident questionnaire, it was carried out it yield Cronbach's Alpha showed $(r=0.93)$ also, regarding suggested solutions questionnaire, it was showed $(r=0.86)$. This indicated that the instrument are reliable.

\section{Pilot study:}

A pilot study will be conducted on $10 \%$ of the sample to ensure the clarity and feasibility of the developed tool and time consuming to fill the final format.

\section{Ethical considerations:}

An official approval to conduct the proposed study was obtained from Ethical Research Committee at the Faculty of Nursing Cairo University. The primary approval was obtained from the administrative line (hospital director), informed consent was obtained from the participates who had the willingness to participate and meet the inclusion criteria. Also they were informed that the study is voluntary and each participants has the right for refusing to participate in the study and has the right to withdraw at any time without any rational. Confidentially of the information was assured, they were informed that data will not be used in any studies without permission.

\section{Procedure:}

An official approval to conduct the proposed study was obtained from Ethical Research Committee at the Faculty of Nursing, Cairo University. The investigator got a letter from Faculty of Nursing seeking for the approval of hospital and nursing director of the 6 October Health Insurance Hospital. After getting approval the investigator explained purpose, nature, and significance of the study for every unit manager. Work schedule of staff nurses were obtained from the head nurse of each unite to plan time for data collection. Questionnaires were handed individually to each unit head nurses or his/her substitution, after determining a date for the interview during morning shift according to the plan of time schedule questionnaires were collected at the same day. After oral explanation, the investigator gave the staff nurses the questionnaire in their working places. The time spent to fill the questionnaire was ranging between 20 to 30 minutes. Data was collected for three months from the beginning of November 2017 till the ending January 2018.

\section{Statistical analysis:}

The collected data will be categorized, scored, tabulated, and analyzed by computer using Statistical Package for Social Science (SPSS) version 20. Descriptive statistics were used: Frequency distribution and percentages. Correlation between variables was evaluated using Pearson's correlation coefficient. Significance was adapted at $p<0.05$ for interpretation of results of tests of significance.

\section{Results}

Table (1): Showed that the majority of the staff nurses $(99.6 \%)$ were female. Regarding their age, $(49.2 \%)$ of them were aged at 35 and more. It also clear that $(74.4 \%)$ of studied sample had technical diploma of nursing, $(91.2 \%)$ of them worked full time. Concerning experience in nursing, $(58 \%)$ of staff had 15 years of experience and more.

Table (2): Showed that the highest mean scores $(2.39 \pm 0.64)$ was regarding to time constrain, while the lowest mean scores $(1.78 \pm 0.74)$ was regarding to lack of education.

Table (3): Showed that the highest mean scores $(2.57 \pm 0.57)$ was for suggested solutions regarding to availability of reports pathways, while the lowest mean scores $(2.30 \pm 0.66)$ was regarding to valuing reporting.

Table (4): Showed that there was no statistical significant relationship between all personal data of studied sample and their perception of total incident reporting barriers except for the item "unusual events are reported in word/unit" ( $\mathrm{F}=3.76$, $p=.0001)$, and also indicated that there was no statistical significant relationship between all personal data of studied sample and their perception of total suggested solutions except for "Department" $(\mathrm{F}=8.074, p=.0001)$. 
Table (1): Percentage distribution of staff nurses regarding their personal characteristics $(\mathrm{N}=250)$.
Table (2): Mean scores of the staff nurses perception regarding barriers of reporting incident dimensions $(n=250)$.

\begin{tabular}{|c|c|c|c|c|c|c|}
\hline Personal characteristics & No & $\%$ & Dimensions & \multicolumn{3}{|c|}{ Mean SD Minimum Maximum } \\
\hline \multicolumn{3}{|l|}{ Agelyears: } & \multirow{2}{*}{$\begin{array}{l}\text { - Culture of shame and } \\
\text { blame }\end{array}$} & \multirow[t]{2}{*}{2.000 .63} & \multirow[t]{2}{*}{1.0} & \multirow[t]{2}{*}{3.0} \\
\hline $20-<25$ & 39 & 15.6 & & & & \\
\hline $25-<30$ & 27 & 10.8 & - Lack of education & $1.78 \quad 0.74$ & 1.0 & 3.0 \\
\hline $30-<35$ & 61 & 24.4 & - Time constraints & 2.390 .64 & 1.0 & 3.0 \\
\hline 35 and more & \multirow[t]{2}{*}{123} & 49.2 & - Sense of futility & $1.98 \quad 0.67$ & 1.0 & 3.0 \\
\hline \multicolumn{2}{|l|}{ Gender: } & & - Lack of feed back & 2.320 .70 & 1.0 & 3.0 \\
\hline Male & 1 & .04 & \multirow{2}{*}{$\begin{array}{l}\text { - Reports view as indicators } \\
\text { of incompetence }\end{array}$} & \multirow[t]{2}{*}{$2.15 \quad 0.77$} & \multirow[t]{2}{*}{1.0} & \multirow[t]{2}{*}{3.0} \\
\hline Female & 249 & 99.6 & & & & \\
\hline \multirow{3}{*}{$\begin{array}{l}\text { Educational qualifications: } \\
\text { Technical diploma of nursing } \\
\text { Technical institutional nursing }\end{array}$} & \multirow{3}{*}{$\begin{array}{l}186 \\
64\end{array}$} & \multirow{3}{*}{$\begin{array}{l}74.4 \\
25.6\end{array}$} & - Total reporting incident & \multirow[t]{3}{*}{$2.08 \quad 0.41$} & \multirow[t]{3}{*}{1.0} & \multirow[t]{2}{*}{3.0} \\
\hline & & & barrier & & & \\
\hline & & & & & & \\
\hline \multirow{3}{*}{$\begin{array}{l}\text { Employment status: } \\
\text { Part time } \\
\text { Full time }\end{array}$} & \multirow{3}{*}{$\begin{array}{l}22 \\
228\end{array}$} & \multirow{3}{*}{$\begin{array}{l}8.8 \\
91.2\end{array}$} & \multirow{2}{*}{\multicolumn{4}{|c|}{$\begin{array}{c}\text { Table (3): Mean scores of staff nurses' perception regarding } \\
\text { suggested solutions dimensions }(n=250) \text {. }\end{array}$}} \\
\hline & & & & & & \\
\hline & & & Dimensions & \multicolumn{3}{|c|}{ Mean SD Minimum Maximum } \\
\hline \multicolumn{2}{|l|}{$\underset{1<5}{\text { Experience in nursing (years): }}$} & 13.2 & - Valuing reporting & 2.300 .66 & 1.0 & 3.0 \\
\hline $5<10$ & 29 & 11.6 & - Availability of reports & \multirow[t]{2}{*}{2.570 .57} & 1.0 & \multirow[t]{2}{*}{3.0} \\
\hline $10<15$ & 43 & 17.2 & pathways & & & \\
\hline 15 and more & 145 & 58.0 & - Feedback and visible & $2.55 \quad 0.61$ & 1.0 & 3.0 \\
\hline \multicolumn{3}{|l|}{ Unusual events are report in word/unit: } & changes & & & \\
\hline Yes & 198 & 79.2 & - Training and education & $2.55 \quad 0.61$ & 1.0 & 3.0 \\
\hline No & 52 & 20.8 & - Total suggested solutions & $2.51 \quad 0.51$ & 1.0 & 3.0 \\
\hline
\end{tabular}

Table (4): Relationship between staff nurses demographic data and their perception of total incident report barriers and total suggested solutions $(\mathrm{n}=250)$.

\begin{tabular}{|c|c|c|c|c|c|c|c|c|}
\hline \multirow[b]{2}{*}{ Personal data } & \multicolumn{4}{|c|}{ Total incident reporting barriers } & \multicolumn{4}{|c|}{ Total suggested solutions } \\
\hline & Mean & SD & $r$ & $p$ & Mean & SD & $r$ & $p$ \\
\hline \multicolumn{9}{|l|}{ Age: } \\
\hline $20-<25$ & 2.1624 & .44625 & -0.06 & 0.31 & 2.5160 & .54273 & 0.03 & 0.6 \\
\hline $25-<30$ & 2.0700 & .30315 & & & 2.5116 & .45104 & & \\
\hline $30-<35$ & 2.0601 & .41664 & & & 2.4283 & .60905 & & \\
\hline 35 and more & 2.0716 & .42199 & & & 2.5518 & .45280 & & \\
\hline \multicolumn{9}{|l|}{ Experience: } \\
\hline $1-<5$ & 2.1759 & .42422 & -0.07 & 0.23 & 2.5341 & .51966 & -0.01 & 0.77 \\
\hline $5-<10$ & 2.1255 & .33164 & & & 2.6185 & .35761 & & \\
\hline $10-<15$ & 2.0065 & .42335 & & & 2.3750 & .62797 & & \\
\hline \multirow[t]{2}{*}{15 and more } & 2.0757 & .42026 & & & 2.5259 & .48884 & & \\
\hline & Mean & SD & $\mathrm{F}$ & $p$ & Mean & SD & $\mathrm{F}$ & $p$ \\
\hline \multicolumn{9}{|l|}{ Gender: } \\
\hline Male & 2.0556 & 0.0 & 0.06 & .947 & 2.6875 & 0.0 & 0.35 & .730 \\
\hline Female & 2.0829 & .41346 & & & 2.5110 & .50937 & & \\
\hline \multicolumn{9}{|l|}{ Educational qualifications: } \\
\hline Technical diploma of nursing & 2.0887 & .42497 & 0.62 & .766 & 2.5280 & .48835 & 0.82 & .570 \\
\hline Associate technical nursing diploma & 2.0604 & .38033 & & & 2.4603 & .56755 & & \\
\hline \multicolumn{9}{|l|}{ Employment status: } \\
\hline Part time & 2.1126 & .50107 & 0.88 & 0.508 & 2.7467 & .20568 & 1.23 & 0.212 \\
\hline Full time & 2.0722 & .40729 & & & 2.4907 & .53010 & & \\
\hline \multicolumn{9}{|l|}{ Department: } \\
\hline Medical & 2.1981 & .39063 & 1.142 & .333 & 2.5842 & .24542 & 8.074 & $.0001 *$ \\
\hline Surgical & 2.0007 & .51117 & & & 2.2484 & .74886 & & \\
\hline ICU & 2.0760 & .38325 & & & 2.3322 & .70787 & & \\
\hline Other & 2.0887 & .39277 & & & 2.6170 & .33761 & & \\
\hline \multicolumn{9}{|l|}{ Unusual events are reported in word/unit: } \\
\hline Yes & 2.0154 & .40392 & 3.76 & $.0001 *$ & 2.4807 & .55210 & 1.53 & .099 \\
\hline No & 2.3458 & .34597 & & & 2.6480 & .25378 & & \\
\hline
\end{tabular}




\section{Discussion}

Incident reporting system in the healthcare setting is intended to make the staff responsive and report the incidents, near miss or sentinel events, so that these could be explored to know the root causes and steps are adopted to reduce their likelihood. The main purpose of the incident reporting system is risk reduction in the hospital and making the system less prone to human errors [24].

The present study was conducted to assess barriers of reporting incident report and suggested solutions from the perspective of staff nurses, results of the present study proved that time constrains was the highest barrier perceived by nurses, from the investigator point of view this might be due to: The hospital provided many types of specialties as it is one of the biggest health insurance hospital in Giza, with high flow of patient, work load, shortage of nursing staff. In addition to crisis mode to do much too quickly, as well as regarding the hospital polices, the hospital having two times of visiting daily, present of more relatives long time, also in the same ward there were multiple patient with different diseases. While the study proved that the lack of education was the lowest barrier as perceived by the nurses this may be due to, the nurses had already participated in different training programs about documentation and importance of reporting incident.

The findings of the present study agree with Banakhar, [21], who reported that the lack of time, increased workload, and the review process that occurs after reporting were considered great barriers to reporting, while regarding lack of education barrier, Noriko [19] added that evidence of improvements in knowledge of and attitude towards patient safety among nurses as a result of the current educational intervention. Patient safety education can have positive effects on knowledge, skills, and attitudes and influence incident reporting.

Results of the present study proved that availability of reports pathways was the highest solution perceived by nurses. From the investigator point of view there is one channel for reporting incident at hospital" paper-based reporting", more pathway as suggested by nurses to be easy and quickly to report incident at any time by many pathways as telephone reporting. While the study proved that the valuing reporting was the lowest solution as perceived by the nurses, this may be due to the hospital created a policy that indicated rewarded department in which a largest number of incident are reported by creation thanks and appreciation at the wall panel. In the same context [22], showed that participants suggested several measures to overcome the barriers and implement successful incident reporting systems, to facilitate staff reporting, including near misses, many participants proposed introducing a rewards system. Regarding to availability of reports pathways, [22] in his study, at Korean General Hospitals, under the title "Barriers to the Operation of Patient Safety Incident Reporting Systems" showed that the use of a variety of reporting channels was recommended for more active incident reporting, such as paper-based reporting, stand-alone or integrated computer-based reporting, and email or telephone reporting, as was the use of different sources to identify the occurrence of incidents, including patient complaints or malpractice claims.

When comparing the demographic data with total incident report barriers, the result revealed that there was no statistical significant relationship between all personal data of studied sample and their perception of total incident reporting barriers except for the item "unusual events are reported in word/unit", this is may be due to the nurses had regular training programs about importance of reporting of unusual event on their patient and organization outcome.

In the same issue Banakhar et al., [21] showed that there was no significant differences between nurses' years of experience and number of barriers to report incidents, except in lack of time and complexity of work particularly with nurses their experience between 11-20 years. Nurses might perceive that get more experience could be related to their underreporting incidents report. This could attributed to the previous clarification in this study that nurses lack of time and complexity of work made the perception in reporting incidents and deal with these barriers sound difficult particularly in nurses with low level of experience.

\section{Conclusion:}

The main barrier for reporting incident barriers was time constrains and the main suggested solutions, was availability of reports pathways.

\section{Recommendations:}

Based on the findings of the present study, the following recommendations were deduced:

1- Training program is recommended to improve incident reporting, reducing fear of reporting, reducing reporting burden, and improving feedback system. 
2- Organization should track the impact of feedback and ensure lessons are learnt to improve safety by reporting and investigating incidents.

3- Increasing support, resources and encourage nurses as they can gain the trust of their seniors to enable them to reported incidents.

4- Safety feedback must share to the medical staff specific vulnerabilities in the healthcare system to raise awareness and must include timely corrective actions to improve safety.

5- The hospital administrators should introduce reward systems, and improving incident reporting systems by including a variety of reporting channels and ensuring reporting anonymity, and creating a strong safety culture within the hospital.

\section{References}

1- SHERMAN, G. CASTRO and M. FLETCHER: "Towards an international classification for patient safety: The conceptual framework," International Journal for Quality in Health Care, Vol. 21 No. 1, pp. 2-8, 2009.

2- SEODERBERG, GRANKVIST, BRULIN and WALLIN: Incident reporting practices in the preanalytical phase: Low reported frequencies in the primary health care setting. Scandinavian Journal of Clinical and Laboratory Investigation, 69: 731-5, 2009.

3- TANJA SCHUB R.N. and MARY WOTEN B.S.N.: Incident Report: Writing, Cinahl Information Systems, 1509 Wilson Terrace, Glendale, CA 91206, 2015.

4- MARY WOTEN R.N.: Incident Report: Writing, Cinahl Information Systems, 1509 Wilson Terrace, Glendale, CA 91206, 2015.

5- HAJIBABAEE F., JOOLAEE S., PEYRAVI H.P., ALIJANY-RENANY H., BAHRANI N. and HAGHANI H.: Journal of Nursing Management, 22: 304-10, 2014.

6- MITCHELL, A. SCHUSTER, K. SMITH and P. PRONOVOST: Patient safety incident reporting: A qualitative study of thoughts and perceptions of experts 15 years after 'To Err is Human, 2016.

7- POLISENA, GAGLIARDI and URBACH: Factors that influence the recognition, reporting and resolution of incidents related to medical devices and other healthcare technologies: A systematic review, 2015.

8- TRAVAGLIA J.F. and HUGHES C.: Cultural and associated enablers of, and barriers to, adverse incident reporting. Qual. Saf. Health Care, 19 (3): 229-33, 2010.

9- MACRAE C.: The problem with incident reporting. B.M.J. Qual. Saf., 25: 71-5, 2016.

10- MARTOWIRONO, JANSMA, VAN LUIJK, WAGNER and BIJNEN: Possible solutions for barriers in incident reporting by residents. J. Eval. Clin. Pract., 18: 76-81, 2012.

11- CHRISTIAANS DINGELHOFF, SMITS, ZWAAN L., LUBBERDING, WAL and WAGNER: To what extent are adverse events found in patient records by patients and healthcare professionals via complaints, claims and incident reports? BioMed Central Health Services Research, 11: 1-10, 2011.

12- MARQUIS and HUSTON: Leadership Roles and Management Functions in Nursing. Lippincott Williams \& Wilkins, Philedelphia, PA.2009.

13- BRAITHWAITE J., WESTBROOK M.T., TRAVAGLIA J.F. and HUGHES C.: Cultural and associated enablers of, and barriers to, adverse incident reporting. Qual. Saf. Health Care, 19 (3): 229-33, 2010.

14- SUOMINEN: Healthcare professionals" knowledge, attitudes and skills regarding patient safety: A systematic literature review. Scandinavian Journal of Caring Sciences, pages 1-21, 2014.

15- ABU AL RUB R.F., AL-AKOUR N.A. and ALATARI N.H.: Perceptions of reporting practices and barriers to reporting incidents among registered nurses and physicians in accredited and nonaccredited Jordanian hospitals. Journal of Clinical Nursing, 24: 2973-82, 2015.

16- EVANS, SMITH, ESTERMAN, et al.: "Evaluation of an intervention aimed at improving voluntary incident reporting in hospitals," Quality and Safety in Health Care, Vol. 16, No. 3, pp. 169-75, 2007.

17- NHS quality improvement Scotland: Incident reporting culture extended national summary report, 2007.

18- LEE W., KIM S.Y., LEE S.I., LEE S.G., KIM H.C., KIM I.: Int. J. Health Plann Manage Oct., 33 (4): 1178-88, Epub 2018 Aug. 30, 2018.

19- NORIKO N., JD1, YUICHI Y., M.D., SHINICHI T. and CHIEMI M.: Effectiveness and Sustainability of Education about Incident Reporting at a University Hospital in Japan, Vol. 20, No. 3, 2014

20- FITZGERALD E., CAWLEY D. and ROWAN N.: Irish staff nurses' perceptions of clinical incident reporting. Int. J. Nurs. Midwifery, 3: 14-21, 2011.

21- BANAKHAR M.A., TAMBOSI A.I., ASIRI S.A., BANJAR Y.B. and ESSA Y.A.: Barriers of Reporting Errors among Nurses in a Tertiary Hospital. Int. J. Nurs. Clin. Pract., 2017.

22- HWANG J.I., LEE S.I. and PARK H.A.: Barriers to the operation of patient safety incident reporting systems in Korean general hospitals. Healthc Inform. Res., 18, 2012.

23- BAKR M., ATALLA: Medication errors, causes and reporting behaviors as perceived by nurses. Journal of Pharma Ceutical And Biomedical Sciences Vol. 19, Issue 19, 2012.

24- ALAM A.Y.: Editorial: Is provision of safe and quality care equivalent to high-tech care? J. Pak. Med. Assoc., 64: 116-7, 2014.

25- EVANS, SMITH, ESTERMAN, et al.: "Evaluation of an intervention aimed at improving voluntary incident reporting in hospitals," Quality and Safety in Health Care, Vol. 16, No. 3, pp. 169-75, 2007.

26- WOLF, HUGHES: Error Reporting and Disclosure. In: Hughes, editor. Patient Safety and Quality: An EvidenceBased Handbook for Nurses. Rockville (MD): Agency for Healthcare Research and Quality (US); Chapter 35, 2008. 


\section{معوقات الإبلاغ عن تقارير الواقعة والحلول المقترحة

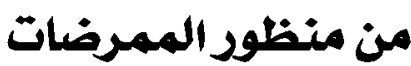

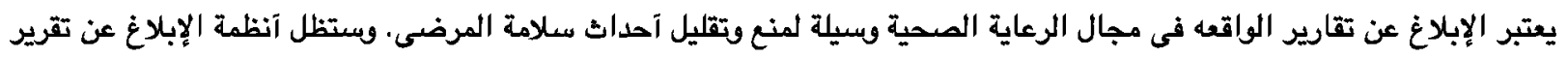

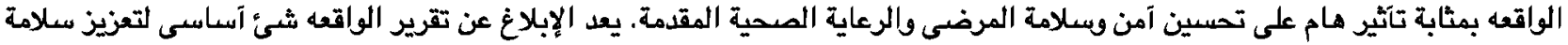

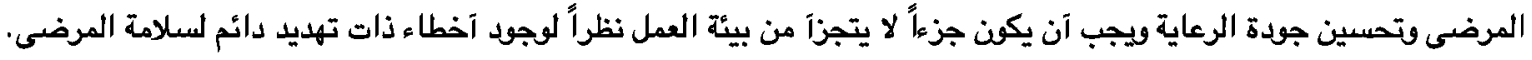
الهدف من البحث: يهدف من هذه الدراسة هو تقييم معققات الإبلاغ عن تقرير الواقعة والحلول المقترحة لحلها من وجهة نظر الممرضين. عينة البحث: إثتملت عينة البحث على مجموعة من الممرضين والممرضات الذين يعملون بالآتسام الداخلية لمستشفى 7 آكتوبر للتآمين

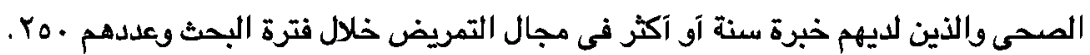
نتائج البحث: آوضحت نتائج البحث آن وجهة نظر المشاركين هى تقيد الوقت من آكثر المعوقات التى تعوق التبليخ عن الواقعة وآن توافر

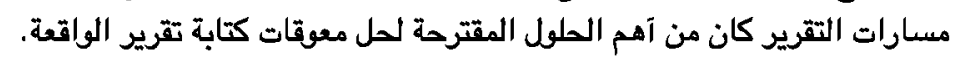

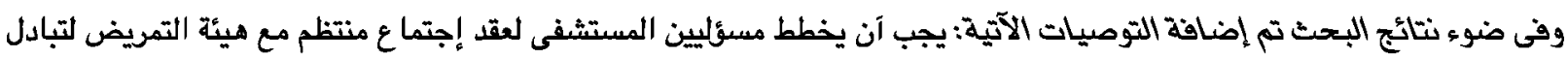

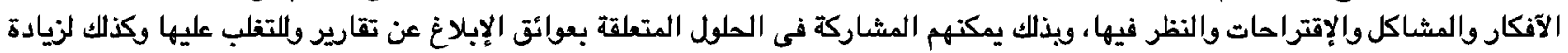

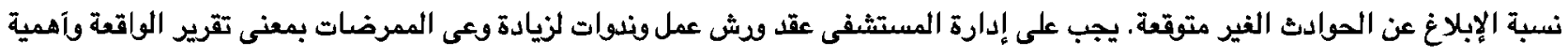

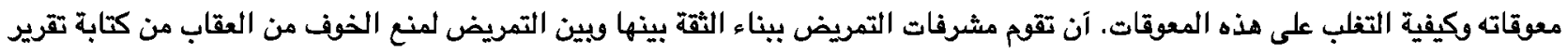
الواقعه. عقد إجتماعات مستمرة مع هيئة التمريض لمعرفة المشاكل والمعوقات التهرئ الخاصة بكتابة تقرير الواقعه والعمل على حلها. 